\title{
Software Architecture Evaluation of Unmanned Aerial Vehicles Fuzzy Based Controllers - A Survey
}

\author{
Elsiddig ahmed Elsiddig \\ College of Graduate Studies \\ Sudan University of Science and Technology \\ Khartoum, Sudan
}

\author{
Hany H Ammar \\ Lane Department of Computer Science and Electrical \\ Engineering \\ College of Engineering and Mineral Resources \\ West Virginia University, Morgantown, WV, USA
}

\begin{abstract}
In this survey paper we discuss the recent techniques for software architecture evaluation methods for Unmanned Aerial Vehicle (UAV) systems that use fuzzy control methodology. We discuss the current methodologies and evaluation approaches, identify their limitations, and discuss the open research issues. These issues include methods used to evaluate the level of risk, communications latency, availability, sensor performance, automation, and human interaction.
\end{abstract}

Keywords: evaluation methods of UAVs, Fuzzy Based Controllers, autonomy evaluation method, full autonomy, performance.

\section{INTRODUCTION}

Researchers around the world have carried much research into the evaluation of unmanned systems, each having their own clear application objectives. Our review of the existing software architecture evaluation methods of the autonomy of unmanned systems has found that these methods include the level evaluation method, double-axis method, three-axis method, look-up table method and formulation method.

There are many different researches work relate to the software architecture evaluation of autonomous navigation control of UAVs; and it content different techniques to develop UAVs control system, include :
a) Fuzzy control technique.
b) Adaptive control technique.
c) Neural networks technique.
d) Genetic algorithms technique.

Then in this survey we focus on the papers that using fuzzy control technique to control all system components.

Fuzzy logic (FL) will be used to tune the PD or PID control gains according to the readings of the sensors, which monitors the condition of the structure and the engine. Since the development of such a hybrid system proves to be time consuming and involves generating many algorithms and models, we only focus on one strand of the hybrid scheme, which is the fuzzy logic control in this research survey. This artificial intelligence system is quite favored for automatic control because it avoids complex non-linear equations and can utilize the best pilot expertise available. Fuzzy logic that is based on the mathematical theory of fuzzy sets circumvents complex differential equations by offering a collection of ifthen rules that operates as a linear function even though the function itself is not known. and this logic does not operate on binary output such as true or false, up or down, left or right, but rather facilitates for the entire intermediate spectrum of outputs to be included. In this research survey, previous fuzzy logic controllers (FLC) are reviewed. [10]

\section{SURVEY OF THE CURRENT SOFTWARE ARCHITECURE EVALUATION METHODS}

Several classical software architecture methods have been widely applied and cited, including Sheridan'sLOA[22, 25], the US military's Autonomous Control Level (ACL)[22] , and Huang's ALFUS[22]. Researchers have extended the above software architecture evaluation methods to various degrees.

For example, using Yang and Zhang [22] put forward the assessment of the autonomy level of unmanned systems by considering four aspects the degree of change in the environment, the degree of task completion, the degree of state stability of the system, and the degree of human computer interaction and then introduced fuzzy theory to this method by quantifying the autonomy level of unmanned systems with a fuzzy decision. Nevertheless the UAV components are not controlled by fuzzy control technique.

From analysis of the mechanism of human intelligence and with in-depth study of the autonomy control-level classification of the UAV, Chen et al.[22] proposed measures of nine-level that evaluate the autonomy control of an unmanned system, and then enriched the content of the autonomy control evaluation level with an autonomy function, autonomy types, intelligence attributes, information sharing capabilities and other aspects. HOWEVER there is no using of fuzzy theory.

Suresh and Ghose [23] carried out measures on 11 levels of autonomy control from single system autonomy to group autonomy, and they provided detailed explanations of each level through published extensive literature on autonomy. They divided each level into several sub layers, and they believed that communication and information would play a key role in realizing the autonomy of an UAV. However there is no using of fuzzy theory.

Many of papers are concerned with the flight of UAVs. proposes fuzzy logic based autonomous flight and landing 
system controllers. All of them using the same three fuzzy logic modules and these modules are developed under the main navigation control system and three more for the autonomous landing control system to control of the altitude, the speed, and the position against the runway, through which the global position (latitude-longitude) of the air vehicle is controlled. A SID (Standard Instrument Departure) and TACAN (Tactical Air Navigation) approach is used and the performance of the fuzzy-based controllers is evaluated with time based diagrams under MATLAB's standard configuration and the (Aerosim) Aeronautical Simulation Block Set which provides a complete set of tools.

The Aerosonde UAV model is always used in the simulations in order to demonstrate the performance and the potential of the controllers. Additionally, some visual tools are deployed in order to get visual outputs that help the designer in the evaluation of the controllers. [4][5][8]

SeferKurnaz Omer Cetin - OkyayKaynak describes other design of compact, and inexpensive fuzzy logic controllers and fuzzy inference systems which estimates the attitude of (UAV), and this attitude refers to parameters of UAV such as longitude latitude, and altitude and angles of rotation known as pitch and roll.

Fuzzy Logic is used to design the Fuzzy Logic Controllers and Fuzzy Inference Systems. Visual simulation tool and Aerosim (Aeronautical Simulation Set) Flight gear interface are used for Simulation purpose.[5]However one UAV mission model used in the simulations

L. Doitsidis, K. P. Valavanisthey has been developed two module fuzzy logic controller that also includes a separate error calculating box is derived for autonomous navigation and control of small manned - unmanned aerial vehicles demonstrating ability to fly through specified way-points in a 3-D environment repeatedly, perform trajectory tracking, and, duplicate another vehicle's trajectory. A MATLAB standard configuration environment and the Aerosim Aeronautical Simulation Block Set are utilized for simulation studies, presented through a visualization interface; results illustrate controller performance and potential. However this design is currently based on human pilot experience and not on flight performance observations. [7].

Kimberly Bickraj discusses the integration of health monitoring and flight control systems for small (UAVs). After briefly reviewing previous fuzzy logic controllers (FLC) of air vehicles, there is very low cost integration method is proposed. The proposed fuzzy logic (FL) selects the best gain values for the operation of PD or PID controllers of the autonomous flight system according to the health of the components. any gain adjustments help the UAV to execute maneuvers in a more conservative manner when the system have structural or proportion system problems. However Once this is successfully established, we will be one-step closer to achieving a completely self- sufficient UAV. [9]

James K. Kuchar civil airspace requires new methods of ensuring collision avoidance. Concerns over command and control latency, vehicle performance, reliability of autonomous functions, and interoperability of sense-and-avoid systems with the Traffic Alert and Collision Avoidance
System (TCAS) and Air Traffic Control must be resolved. his paper describes the safety evaluation process that the international community has deemed necessary to certify such systems. The process focuses on a statistically-valid estimate of collision avoidance performance developed through a combination of airspace encounter modeling, fast time simulation of the collision avoidance system across millions of encounter scenarios, and system failure and event sensitivity analysis.

However, all aircraft are required to be transponder -equipped. Extensive flight testing is required to support modeling communications latency and availability, sensor performance, automation, human interaction with CAS advisories, and flight characteristics.[ 1 ]

Meng-Lun fixed-wing UAV based spatial information acquisition platform is developed and evaluated the evaluation Approach used is comparing DG results with checking points with precisely known coordinates. To evaluated direct Georeference( DG) accuracy, Interior Orientation Parameters (IOP) and Exterior Orientation Parameters (EOP). However the Extended Kalman Filter(EKF) trajectory is not smooth [ 2 ].

DemozGebredevelop a framework for the design of CONOPs, which take these SUAS limitations into account. The method outlined shows, in part, how these vehicle/infrastructure collision risks can be estimated or conservatively bounded. his evaluation Approach used is resorting and multi-sensor on board to evaluate Risk, vehicle states, traffic management parameters, and sensor performance. However the performance specifications provided by manufactures does not provide sufficient information to allow precisely quantifying or bounding the collision risk.[3]

Roopashree.S, Shubha Bhat. they estimates the attitude of UAVs. they used Kalman filter fuzzy approach to generate fuzzy rules. (Kalman Filtering is a form of optimal estimation characterized by recursive evaluation) and they have internal model of dynamics of system being estimated. However The attitude of UAV may oscillate because the controller design is based on human pilot experience.[6]

\section{OPEN ISSUES}

After having studied the literature on evaluating autonomous control of UAVs we can say that :

a. There was no systematic study that could provide a full autonomy evaluation method for fuzzy logic based control system of UAVs.

b. There are still many problems with the adaptability of existing evaluation methods, which need to be improved for general utilization.

c. The autonomy evaluation method of the UAV must consider the diversity, multidimensionality, hierarchy, and primary and secondary natures of the application target and the system itself, so that it can 
avoid ambiguity in the formulation and description

of the autonomy of autonomous UAV.

Table 1. Examples of Approaches for Software

Architecture Evaluation of UAVs:

\begin{tabular}{|c|c|c|c|c|c|}
\hline & $\begin{array}{l}\text { Author } \\
\text { Name/Year }\end{array}$ & Objective & $\begin{array}{l}\text { evaluation } \\
\text { Approach used }\end{array}$ & $\begin{array}{l}\text { Elements or } \\
\text { attributes that } \\
\text { evaluated }\end{array}$ & Limitation \\
\hline 1 & $\begin{array}{l}\text { SeferKurnaz } \\
\text {-Omer Cetin } \\
\text { OkyayKayna } \\
\text { k(2009) }\end{array}$ & $\begin{array}{l}\text { provides autonomy to } \\
\text { the UAV in all } \\
\text { phases of a typical } \\
\text { UAV's mission } \\
\text { except take off and } \\
\text { land on. }\end{array}$ & $\begin{array}{l}\text { MATLAB's standard } \\
\text { configuration and the } \\
\text { Aerosim } \\
\text { Aeronautical } \\
\text { Simulation Block Set }\end{array}$ & $\begin{array}{l}\text { performance of the } \\
\text { fuzzy based } \\
\text { controllers } \\
\text { components }\end{array}$ & $\begin{array}{l}\text { there exist some oscillations and } \\
\text { errors when wind effects are added } \\
\text { to the simulation environment one } \\
\text { UAV mission model used in the } \\
\text { simulations }\end{array}$ \\
\hline 2 & $\begin{array}{l}\text { Omer Cetin } \cdot \\
\text { SeferKurnaz } \\
\cdot \\
\text { OkyayKayna } \\
\text { k (2011) }\end{array}$ & $\begin{array}{l}\text { Design of } \\
\text { Autonomous Landing } \\
\text { System for } \\
\text { Unmanned Aerial } \\
\text { Vehicles }\end{array}$ & $\begin{array}{l}\text { MATLAB's standard } \\
\text { configuration and the } \\
\text { Aerosim } \\
\text { Aeronautical } \\
\text { Simulation Block }\end{array}$ & $\begin{array}{l}\text { performance of the } \\
\text { fuzzy based } \\
\text { controllers } \\
\text { components }\end{array}$ & $\begin{array}{l}\text { there exist some oscillations and } \\
\text { errors when wind effects are added } \\
\text { to the simulation environment.. one } \\
\text { UAV mission model used in the } \\
\text { simulations }\end{array}$ \\
\hline 3 & $\begin{array}{l}\text { SeferKurnaz } \\
\text {, Omer Çetin } \\
\text { (2010) }\end{array}$ & $\begin{array}{l}\text { Autonomous } \\
\text { Navigation and } \\
\text { Landing Tasks for } \\
\text { Fixed Wing Small } \\
\text { (UAV) }\end{array}$ & $\begin{array}{l}\text { MATLAB's standard } \\
\text { configuration and the } \\
\text { Aerosim } \\
\text { Aeronautical } \\
\text { Simulation Block }\end{array}$ & $\begin{array}{l}\text { performance of the } \\
\text { fuzzy based } \\
\text { controllers } \\
\text { components }\end{array}$ & $\begin{array}{l}\text { low tuning of membership } \\
\text { functions. Autonomous takeoff not } \\
\text { tried. } \\
\text { one UAV mission model used in } \\
\text { the simulations }\end{array}$ \\
\hline 4 & $\begin{array}{l}\text { L. Doitsidis, } \\
\text { K. P. } \\
\text { Valavanis } \\
\text { (2004) }\end{array}$ & $\begin{array}{l}\text { ability to fly through } \\
\text { specified waypoints } \\
\text { in a 3-D environment } \\
\text { repeatedly }\end{array}$ & Fuzzy Logic Based & $\begin{array}{l}\text { controller } \\
\text { performance }\end{array}$ & $\begin{array}{l}\text { Design is currently based on } \\
\text { human pilot experience and not on } \\
\text { flight performance observations. }\end{array}$ \\
\hline 5 & $\begin{array}{l}\text { KimberlyBic } \\
\text { kraj,Thierry } \\
\text { Pamphile } \\
\text { (2006) }\end{array}$ & $\begin{array}{l}\text { selects the best gain } \\
\text { values for the } \\
\text { operation of PD or } \\
\text { PID controllers of the } \\
\text { autonomous flight } \\
\text { system according to } \\
\text { the health of the } \\
\text { components. }\end{array}$ & $\begin{array}{l}\text { fuzzy logic based } \\
\text { neuro-fuzzy inference } \\
\text { system (ANFIS). }\end{array}$ & $\begin{array}{l}\text { performance of the } \\
\text { fuzzy based } \\
\text { controllers } \\
\text { components }\end{array}$ & $\begin{array}{l}\text { Once this is successfully } \\
\text { established, we will be one-step } \\
\text { closer to achieving a completely } \\
\text { self- sufficient UAV. }\end{array}$ \\
\hline 6 & $\begin{array}{l}\text { James K. } \\
\text { Kuchar }\end{array}$ & $\begin{array}{l}\text { Safety analysis } \\
\text { methodology for } \\
\text { (UAV) collision } \\
\text { avoidance systems }\end{array}$ & $\begin{array}{l}\text { statistically-valid } \\
\text { estimate }\end{array}$ & $\begin{array}{l}\text { Risk ratio, } \\
\text { communications } \\
\text { latency, availability, } \\
\text { sensor performance, } \\
\text { automation, human } \\
\text { interaction. }\end{array}$ & $\begin{array}{l}\text { 1- UAV concepts need to go } \\
\text { through a similar process involving } \\
\text { detailed airspace encounter } \\
\text { modeling, dynamic simulation of } \\
\text { collision avoidance system } \\
\text { performance, and system failure } \\
\text { and event sensitivity studies. } \\
2 \text {-Flight tests and human-in-the- } \\
\text { loop simulation studies are also } \\
\text { required to develop models to } \\
\text { describe how UAV pilots (or an } \\
\text { autonomous system) would } \\
\text { respond to collision avoidance }\end{array}$ \\
\hline
\end{tabular}




\begin{tabular}{|c|c|c|c|c|c|}
\hline & & & & & system advisories. \\
\hline 7 & $\begin{array}{l}\text { Meng-Lun } \\
\text { (2012) }\end{array}$ & $\begin{array}{l}\text { fixed-wing UAV } \\
\text { based spatial } \\
\text { information } \\
\text { acquisition platform } \\
\text { is developed and } \\
\text { evaluated. }\end{array}$ & $\begin{array}{l}\text { comparing DG } \\
\text { results with checking } \\
\text { points with precisely } \\
\text { known coordinates }\end{array}$ & $\begin{array}{l}\text { DG accuracy, Interior } \\
\text { Orientation } \\
\text { Parameters (IOP) } \\
\text { Exterior Orientation } \\
\text { Parameters (EOP) }\end{array}$ & EKF trajectory is not smooth \\
\hline 8 & $\begin{array}{l}\text { DemozGebr } \\
\text { e- } \\
\text { EgziabherZh } \\
\text { iqiang Xing } \\
2011\end{array}$ & $\begin{array}{l}\text { develop a framework } \\
\text { for the design of } \\
\text { CONOPs, which take } \\
\text { these SUAS } \\
\text { limitations into } \\
\text { account. The method } \\
\text { outlined shows, in } \\
\text { part, how these } \\
\text { vehicle/infrastructure } \\
\text { collision risks can be } \\
\text { estimated or } \\
\text { conservatively } \\
\text { bounded. }\end{array}$ & $\begin{array}{l}\text { Resorting. } \\
\text { Multi- sensor. }\end{array}$ & $\begin{array}{l}\text { Risk. } \\
\text { vehicle states . other } \\
\text { traffic management } \\
\text { parameters. sensor } \\
\text { performance. }\end{array}$ & $\begin{array}{l}\text { The performance specifications } \\
\text { provided by manufactures does not } \\
\text { provide sufficient information to } \\
\text { allow precisely quantifying or } \\
\text { bounding the collision risk. }\end{array}$ \\
\hline 9 & $\begin{array}{l}\text { Roopashree. } \\
\text { S, Shubha } \\
\text { Bhat } \\
\text { (2012) }\end{array}$ & $\begin{array}{l}\text { estimates the attitude } \\
\text { of (UAV) }\end{array}$ & $\begin{array}{l}\text { Kalman filter fuzzy } \\
\text { approach is used to } \\
\text { generate fuzzy rules. } \\
\text { Kalman Filtering is a } \\
\text { form of optimal } \\
\text { estimation } \\
\text { characterized by } \\
\text { recursive evaluation }\end{array}$ & $\begin{array}{l}\text { internal model of } \\
\text { dynamics of system } \\
\text { being estimated. }\end{array}$ & $\begin{array}{l}\text { The attitude of UAV may oscillate } \\
\text { because } \\
\text { the controller design is based on } \\
\text { human pilot experience. }\end{array}$ \\
\hline
\end{tabular}

\section{CONCLUSION}

This survey paper concern with software architecture evaluation of unmanned aerial vehicles fuzzy based controllers.

In the literature many approaches to architecture evaluation can be identified, i.e., simulation, scenarios, mathematical modeling, and experience based reasoning. Here we present some evaluation approach and what are the elements or attributes that evaluated and what is there limitation. Then we find an interesting open issue about the evaluation on autonomous degree and performance of system controller's components of UAVs.

From our survey there are still many problems with the adaptability of existing evaluation methods, which need to be improved for general utilization. The autonomy evaluation

method of the UAV must consider the diversity, multidimensionality, hierarchy, and primary and secondary natures of the application target and the system itself, so that it can avoid ambiguity in the formulation and description of the autonomy of autonomous UAV.

\section{REFERENCES}

[1] James K. Kuchar, MIT Lincoln Laboratory" SAFETY ANALYSIS METHODOLOGY FOR UNMANNED

\section{AERIALVEHICLE (UAV) COLLISION AVOIDANCE SYSTEMS".}

[2] Meng-Lun Tsai a, *, Kai-Wei Chiang a, Yi-Hsing Tseng a, Jiann-You Rau a, Yun-Wen Huang a, Cheng-Fang Lo b "THE PERFORMANCE ANALYSIS OF A UAV BASED MOBILE MAPPING SYSTEM “ Dept. of Geomatics, National Cheng Kung University, Taiwanb GeoSat Informatics Technology Corporation, Taiwan

[3] DemozGebre-EgziabherZhiqiang Xing March 2011 “ Analysis of Unmanned Aerial Vehicles Concept of Operations in ITS Applications" Department of Aerospace Engineering \& Mechanics University of Minnesota

[4]. SeferKurnaz · Omer Cetin · OkyayKaynak." Fuzzy Logic Based Approach to Design of Flight Control and Navigation Tasks for Autonomous Unmanned Aerial Vehicles”Received: 
15 March 2008 / Accepted: 30 June 2008 / Published online: 1 October 2008 ○ Springer Science + Business Media B.V. 2008

[5]. Omer Cetin 1, SeferKurnaz 2, Okyay Kaynak1,3 "Fuzzy Logic Based Approach to Design of Autonomous Landing System for Unmanned Aerial Vehicles “ 1. Turkish Air Force Academy, ASTIN o.cetin@hho.edu.tr, Yesilyurt, Istanbul, 34807 Turkey 2. Turkish Air Force Academy, ASTIN Yesilyurt, Istanbul, 34807 Turkey 3. Department of Electrical and Electronic Engineering, Bogazici University, o.kaynak_at_ieee.org, Bebek, 80815 Istanbul / Turkey

[6]Roopashree.S \#1, Shubha Bhat\#3:Deepika K.M \#2 "Fuzzy Kalman Approach to Control the Navigation of Unmanned Aerial Vehicles“ 1, 3 Department of Computer Science and Engineering, Dayananda Sagar College of Engineering, Affiliated to VTU, Bangalore-560078, India.2 Department of Information Science and Engineering, NitteMeenakshiInstiute of Technology, Affiliated to VTU, Bangalore-560064, India.

[7] L. Doitsidis, K. P. Valavanis 1 N. C. Tsourveloudis, M. Kontitsis2 "A Framework for Fuzzy Logic Based UAV Navigation and Control 1- Dept. of CSEE, CRASAR University of South Florida Tampa, FL 33620 2- Dept. of Production Engineering and Management Technical University of Crete Chania 73100, Crete, Greece

[8]. SeferKurnaz, Omer Çetin "Autonomous Navigation and Landing Tasks for Fixed Wing Small Unmanned Aerial Vehicles" Turkish Air Force Academy, ASTIN Yesilyurt, Istanbul, 34807 Turkey

[9]. Kimberly Bickraj 1,Aylin Yenilmez2, Ming Li, Ibrahim N3 "Fuzzy Logic Based Integrated Controller for Unmanned Aerial Vehicles"1. Thierry Pamphile Florida International University Department of Mechanical and Materials Engineering .2. Istanbul Technical University Faculty of Mechanical EngineeringGumussuyu, Istanbul 34439 Turkey

3. Tansel Florida International University Department of Mechanical and Materials Engineering

[10]. SWETHA PANDHITI"Blackboard Architecture for An Unmanned Aerial Vehicle Controller Using Fuzzy Inference Systems.“ B.Tech, Jawaharlal Nehru Technological University Hyderabad, Andhra Pradesh, India.

[11]. Dufrene, W.R., Jr. “Application of artificial intelligence techniques in uninhabited aerial vehicle flight. " In: The 22nd Digital Avionics Systems Conference vol. 2, pp. 8.C.3-8.1-6 (2003)
[12]. Li, Y., Sundararajan, N., Sratchandran, P. "Neurocontroller design for nonlinear fighter aircraft maneuver using fully tuned RBF networks" . Automatica 37, 1293-1301 (2001)

[13]. Borrelli, F., Keviczky, T., Balas, G.J "Collision-free UAV formation flight using decentralized optimization and invariant sets". In: 43rd IEEE Conference on Decision and Control vol. 1, pp. 1099-1104 (2004)

[14].Marin, J.A., Radtke, R., Innis, D., Barr, D.R., Schultz,A.C" Using a genetic algorithm to develop rules to guide unmanned aerial vehicles" In: Proceedings of the IEEE International Conference on Systems, Man, and Cybernetics, vol. 1, pp. 1055-1060. (1999)

[15]. Ren, W., Beard, R.W.“ CLF-based tracking control for UAV kinematic models with saturationconstraints". In: Proceedings of the 42nd IEEE Conference on Decision and Control, vol. 4, pp.3924-3929 (2003)

[16]. Dathbun, D., Kragelund, S., Pongpunwattana, A., CapozziB.: "An evolution based path planning algorithm for autonomous motion of a UAV through uncertain environments" .In: Proceedings of the 21st Digital Avionics Systems Conference vol. 2, pp. 8D2-1-8D2-12 (2002)

[18].Global Robotic Observation System, Definition OfAerosonde UAV Specifications: http://www.aerosonde.com/aircraft/

[19].Unmanned Dynamics, Aerosim Aeronautical Simulation Block Set Version 1.2 User's Guide: http://www.udynamics.com/aerosim/default.htm

[20]. FlightGear Open-source Flight Simulator. www.flightgear.org

[21]. Qiau, W., Muzimoto, M.: "PID type fuzzy controller and parameter adaptive method". Fuzzy Sets Syst. 78, 23-35 (1995),

[22] Huang H M. In: Messina E, Madhavan R, eds“Autonomy Levels for Unmanned Systems (ALFUS) framework: Safety and application issues.." Proceedings of the Performance Metrics for Intelligent Systems Workshop, 2007 Aug 28-30, Washington DC USA, ACM New York NY USA Press, 2007. $48-53$

[23] Suresh M, Ghose D“Role of information and communication in redefining unmanned aerial vehicle autonomous control levels..” P I MechEng G-J Aer, 2010, 224: $171-197$ 
[24] , Y. Zhao, Y. Yao, “Autopilot Design for Aerial Vehicles with Aerodynamic Surfaces and Lateral Jets Using Explicit Hybrid" MPC 1600 hrs AIAA-2015-0864 B. YangHarbin Institute of Technology, Harbin, China 101

[25] Defense Science Board "TASK FORCE REPORT: The Role of Autonomy in DoD Systems," Department of Defense, July 2012.

\section{AUTHORS BIOGRAPHIES}

Elsiddig ahmed Elsiddig

College of Graduate Studies

Sudan University of Science and Technology,

Khartoum, Sudan a $\mathrm{PhD}$ candidate in computer science since 2013.

Hany H. Ammar BSEE, BSPhysics, MSEE, and PhD EE, is a Professor of Computer Engineering in the Lane Computer Science and Electrical Engineering department at West Virginia University. He has published over 170 articles in prestigious international journals and conference proceedings. $\mathrm{He}$ is currently the Editor in Chief of the Communications of the Arab Computer Society On-Line Magazine. He is serving and has served as the Lead Principal Investigator in projects funded by the Qatar National Research Fund under the National Priorities Research Program. In 2010 he was awarded a Fulbright Specialist Scholar Award in Information Technology funded by the US State Department - Bureau of Education and Cultural Affairs. He has been the Principal Investigator on a number of research projects on Software Risk Assessment and Software Architecture Metrics funded by NASA and NSF, and projects on Automated Identification Systems funded by NIJ and NSF. He has been teaching in the areas of Software Engineering and Computer Architecture since 1987. In 2004, he co-authored a book entitled PatternOriented Analysis and Design: Composing Patterns to Design Software Systems, Addison-Wesley. In 2006, he co-authored a book entitled Software Engineering: Technical, Organizational and Economic Aspects, an Arabic Textbook. Dr. Ammar is a member of the IEEE and the ACM professional organizations. He has served as Chairman and member of Steering Committees and Program Committees of several International Conferences, Workshops, and Symposia. 